\title{
Visualization of Charge Distribution in a Lithium Battery Electrode
}

\author{
Jun Liu, ${ }^{\mathrm{a}}$ Martin Kunz, ${ }^{\mathrm{b}}$ Kai Chen, ${ }^{\mathrm{b}}$ Nobumichi Tamura, ${ }^{\mathrm{b}}$ and Thomas J. Richardson ${ }^{* a}$ \\ ${ }^{a}$ Environmental Energy Technologies Division and ${ }^{b}$ Advanced Light Source \\ Lawrence Berkeley National Laboratory \\ Berkeley, California 94720, USA
}

* To whom correspondence should be addressed. E-mail: tjrichardson@lbl.gov. Tel.: +1-510486-8619. Fax: +1-510-486-8609. 


\begin{abstract}
:
We describe a method for direct determination and visualization of the distribution of charge in a composite electrode. Using synchrotron x-ray microdiffraction, state-of-charge profiles inplane and normal to the current collector were measured. In electrodes charged at high rate, the signatures of non-uniform current distribution were evident. The portion of a prismatic cell electrode closest to the current collector tab had the highest state of charge, due to electronic resistance in the composite electrode and supporting foil. In a coin cell electrode, the active material at the electrode surface was more fully charged than that close to the current collector because the limiting factor in this case is ion conduction in the electrolyte contained within the porous electrode.
\end{abstract}

\title{
TOC Graphic:
}

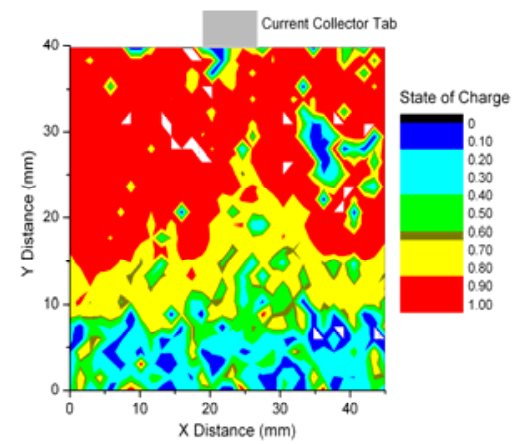

Keywords: Energy storage, batteries, charge distribution, polarization, electrochemical characterization, microdiffraction. 
Lithium ion batteries have made a great impact on consumer electronics and are about to revolutionize the transportation area. ${ }^{1}$ Although they were introduced almost two decades ago, there are still some "black boxes", such as charge distribution within battery electrodes. Nonuniform charge distribution within battery electrodes may impact performance in a variety of ways, including reduced energy and power, underutilization of capacity, localized heat generation, and overcharge or overdischarge. While several current distribution models have been developed, ${ }^{2-10}$ there has been no simple way to obtain experimental data on composite electrodes such as those used in lithium-ion batteries. Dynamic potentiometric methods such as those employed by Díez-Pérez et al. ${ }^{11}$ are not readily applicable to the thin composite electrodes of lithium-ion cells. Sever Skapin et al. ${ }^{12}$ measured local conductivities in composite electrodes using microcontact impedance spectroscopy, but the method does not address the current distribution in the electrode as a whole. Kim et al. ${ }^{9,10}$ measured in-plane thermal profiles of thin $\mathrm{Li}(\mathrm{NiCoMn}) \mathrm{O}_{2}$ batteries, which reflect the current distribution during discharge. When an active material undergoes charge and discharge via a two-phase mechanism, as is the case with $\mathrm{LiFePO}_{4}$, although there is minor relaxation of concentration gradients in the electrolyte upon interrupting the charge or discharge current, redistribution of charge within the active material is negligible. Here we present a novel experimental method for direct determination and visualization of the charge distribution in a composite electrode using synchrotron $\mathrm{x}$-ray microdiffraction. ${ }^{13} \mathrm{LiFePO}_{4}$ was chosen as active material for this study, because (i) it is a safe and promising cathode material for plug-in hybrid electric vehicle application; ${ }^{14}$ (ii) its twophase charge-discharge reaction produces a charge distribution that is "frozen" when the current is interrupted. ${ }^{15}$ Since non-uniform charge distribution may develop either in the cross section or in the plane of the electrode depending on cell configuration and current density, two $\mathrm{LiFePO}_{4}$ 
composite electrodes in different cell configurations were studied. One was a circular electrode (diameter is $13 \mathrm{~mm}$ ) in a Swagelok-type cell (equivalent to a coin cell), in which the charge distribution is non-uniform in cross section at high current density. The other was a larger rectangular electrode $(40 \mathrm{~mm} \times 45 \mathrm{~mm})$ with a tab centered at one end in a "pouch cell" configuration, in which the charge distribution varies in-plane.

The cross section of the circular $\mathrm{LiFePO}_{4}$ electrode is shown in the scanning electron microscope (SEM) image in Figure 1 a. Due to its small size, an Fe x-ray fluorescence image was used to locate the area of interest, and the approximate locations of vertical and horizontal xray microdiffraction $(\mu \mathrm{XRD})$ scans are shown in Figure $1 \mathrm{~b}$. In an electrode charged to $50 \%$ overall SOC (state of charge) at a current density of $20 \mathrm{~mA} \mathrm{~g}^{-1}$ of active material (a rate of $0.11 \mathrm{C}$, where $\mathrm{C}$ is the rate at which the full charge capacity is delivered in one hour), the $\mathrm{FePO}_{4}$ phase concentration, which reflects the local SOC, was nearly constant in both the vertical (perpendicular to the current collector, Figure $1 \mathrm{c}$ ) and horizontal (in-plane, Figure $1 \mathrm{~d}$ ) directions. When the charging rate was increased to $3 \mathrm{~A} \mathrm{~g}^{-1}$ (18 C), the SOC was high at the top surface of the electrode and decreased steadily as it neared the current collector (Figure $1 \mathrm{e}$ ). The in-plane distribution (Figure $1 \mathrm{f}$ ) remained constant. During charging, lithium ions are extracted from the cathode and diffuse toward the anode, producing a concentration gradient within the electrolyte and drawing anions toward the cathode. The reverse is true on discharging. Nonaqueous lithium electrolytes have limited ion conductivities and the ion diffusion paths in the porous electrode are narrow and tortuous. At low charge/discharge rates, diffusion in the electrolyte phase is sufficient to maintain uniform charging at all depths in the porous electrode. If the charging rate is high, however, the electrolyte at the greatest distance from the anode may 
becomes sufficiently polarized that charging is impeded, and only the portions near the separator can participate fully in the charging process. 

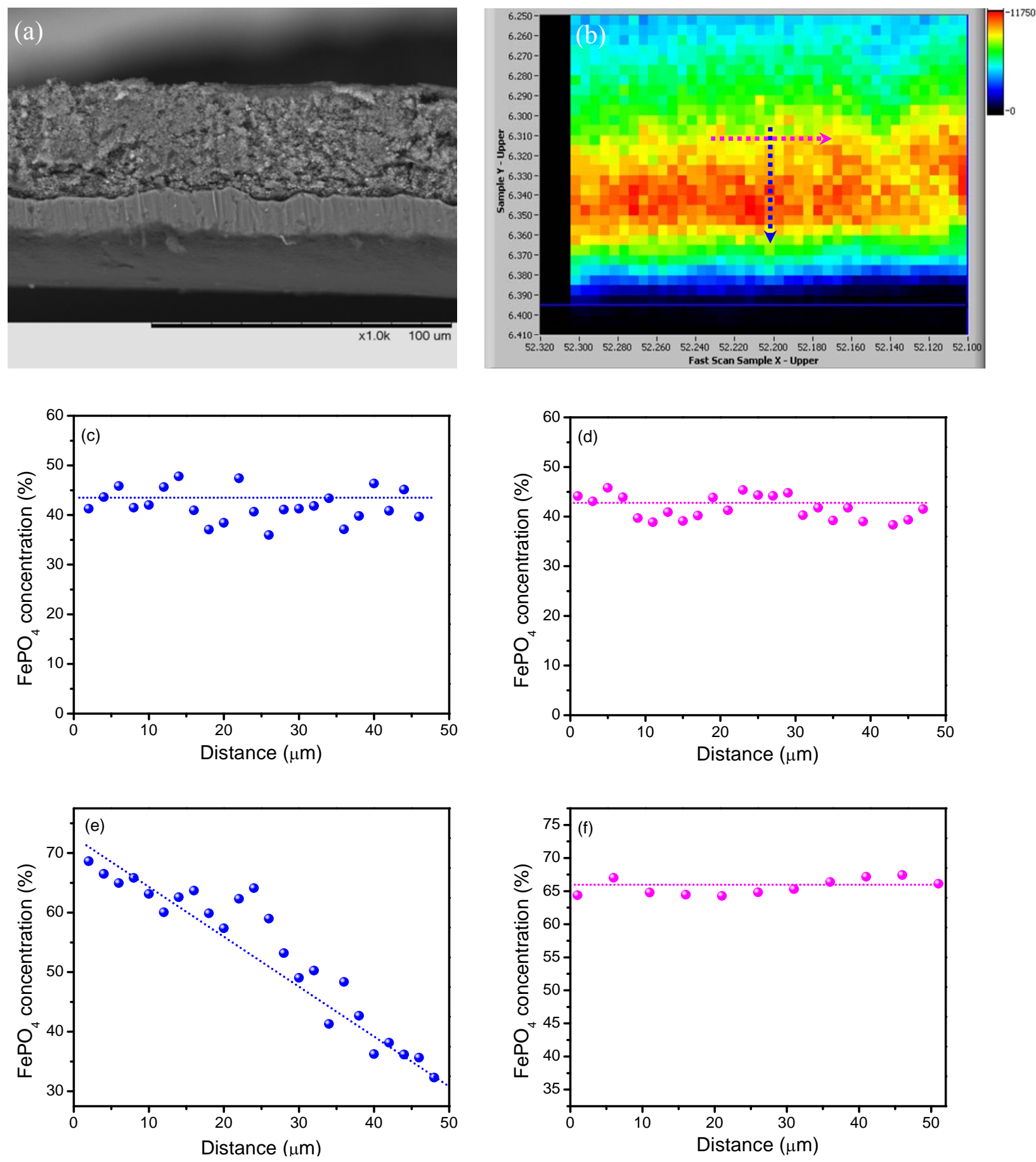

Figure 1. (a) SEM image; (b) Fe fluorescence image of the cross-section of a circular $\mathrm{LiFePO}_{4}$ electrode. The approximate locations of the vertical and horizontal scans are superimposed. $\mathrm{FePO}_{4}$ phase concentration vs. scan distance along (c) vertical direction and (d) horizontal direction of the electrode at $50 \% \mathrm{SOC}$ (charged at $20 \mathrm{~mA} \mathrm{~g}^{-1}$ ). $\mathrm{FePO}_{4}$ phase concentration vs. scan distance along (e) vertical direction and (f) horizontal direction of the $\mathrm{LiFePO}_{4}$ electrode at $50 \%$ SOC (charged at $3 \mathrm{~A} \mathrm{~g}^{-1}$ ). 
Commercial rechargeable lithium ion batteries consist of many layers of rectangular electrodes and separators in prismatic stacks or spirally wound, with current collector tabs at the edges of the electrodes. In contrast to the coin cell configuration, electronic conductivity in the plane of the electrodes influences the charge distribution. This is shown graphically in Figure 2. A rectangular electrode with a tab centered at one end was charged at $2 \mathrm{~A} \mathrm{~g}^{-1}$ (12 C) to an average SOC of $50 \%$ in a single layer "pouch cell" configuration similar to that found in a prismatic stack. The phase distribution (Figure $2 \mathrm{~b}$ ) shows a high SOC near the tab, steadily decreasing toward the unconnected end. Also notable are islands of uncharged areas in the charged regions. These represent portions of the electrode that have been isolated by delamination or cracking during electrode cutting and/or cell assembly. ${ }^{16}$ The somewhat higher SOC evident along the sides of the electrode is probably due to reduced electrolyte polarization in the presence of excess electrolyte in the separator extending beyond the active area of the cell.
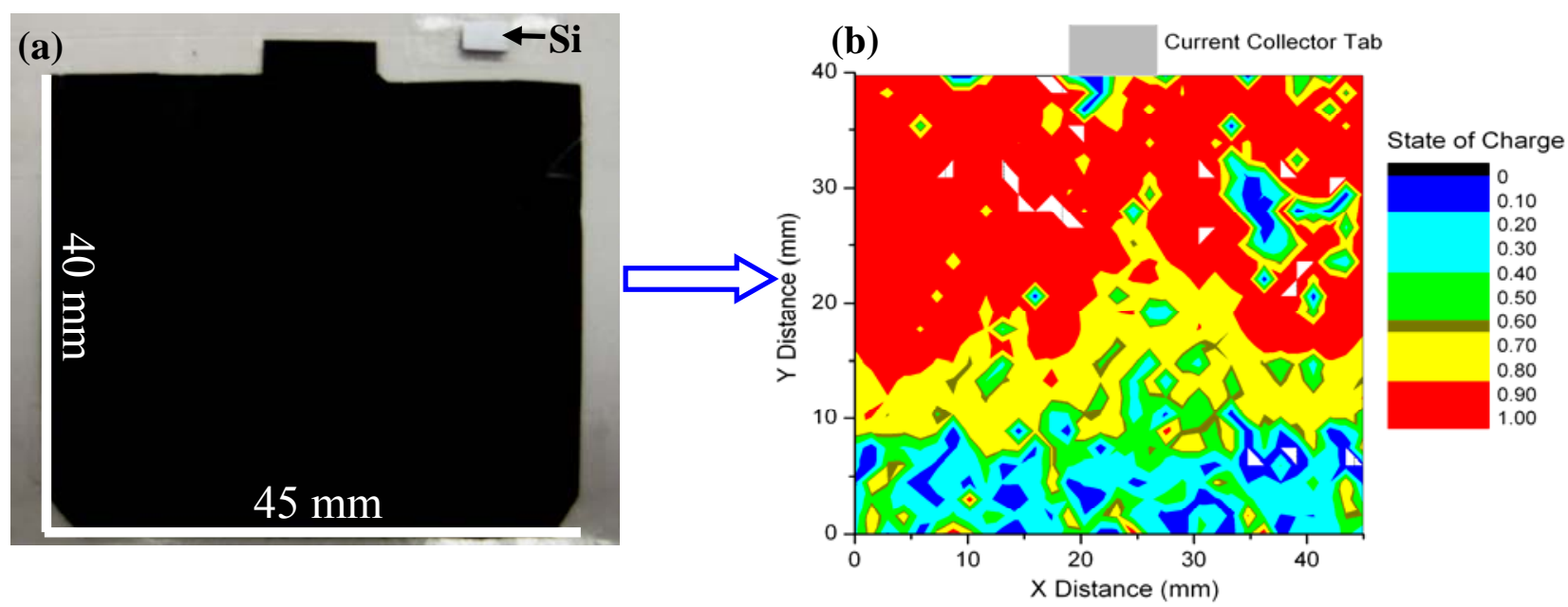

Figure 2. (a) Optical image of the $40 \mathrm{~mm} \times 45 \mathrm{~mm}$ rectangular $\mathrm{LiFePO}_{4}$ electrode; (b) $\mathrm{FePO}_{4}$ phase concentration profile of the prismatic electrode at $50 \% \mathrm{SOC}$ (charged at $2 \mathrm{~A} \mathrm{~g}^{-1}$ ). 
Examination of electrodes prepared with different porosities, thicknesses and loadings, in conjunction with the use of models will be used to develop improved electrode architecture that will maximize performance and utilization in lithium ion cells.

\section{EXPERIMENTAL METHODS}

An $\mathrm{LiFePO}_{4}$ composite laminate with a thickness of about $50 \mu \mathrm{m}$ was fabricated by coating an aluminum foil current collector with a slurry comprising $80 \mathrm{wt}$ \% C-coated $\mathrm{LiFePO}_{4}$ powder (kindly provided by IREQ, Montreal, Canada), $10 \mathrm{wt.} \%$ carbon black and $10 \mathrm{wt} . \%$ polyvinylidene difluoride binder. Two discs $13 \mathrm{~mm}$ in diameter were assembled into Swageloktype cells with lithium foil anodes, Celgard polypropylene separators, and $1 \mathrm{M} \mathrm{LiPF}_{6}$ electrolyte in 1:1 ethylene carbonate/diethylcarbonate. After one charge and discharge at $20 \mathrm{~mA} / \mathrm{g}$ to assess their capacity, the electrodes were charged to $50 \% \mathrm{SOC}$ at $20 \mathrm{~mA} / \mathrm{g}$ and $3 \mathrm{~A} / \mathrm{g}$, respectively. A thinner $(<30 \mu \mathrm{m}) \mathrm{LiFePO}_{4}$ laminate was cut into a $40 \mathrm{~mm} \times 45 \mathrm{~mm}$ rectangle. This electrode was charged to $50 \% \mathrm{SOC}$ at $2 \mathrm{~A} \mathrm{~g}^{-1}$ in a beaker cell after one charge and discharge at $\mathrm{C} / 5$ rate. The electrodes were removed and rinsed with dimethylcarbonate to remove the residual electrolyte. After vacuum drying overnight at $80^{\circ} \mathrm{C}$, the circular electrodes were cast into epoxy and sliced to expose their cross-sections.

The x-ray microdiffraction experiments were conducted on beamline 12.3.2 at the Advanced Light Source in Lawrence Berkeley National Laboratory. The samples were step scanned using a monochromatic $(6.02 \mathrm{keV}) \mathrm{x}$-ray beam $2 \mu \mathrm{m} \times 5 \mu \mathrm{m}$ for the cross-section scans and $2 \mu \mathrm{m} \times 25 \mu \mathrm{m}$ for the in-plane scan. At each step a diffraction pattern was collected using a MAR133 x-ray CCD detector at a distance of $390 \mathrm{~mm}$ from the sample and at an angle of $45^{\circ}$ with respect to the beam. For the cross-section, line scans were measured both perpendicular and 
parallel to the $\mathrm{Al}$ substrate with a step size of $2 \mu \mathrm{m}$. For the in-plane study, two-dimensional (2-D) scan were performed with a step size of 140 micrometers. The x-ray scan diffraction data were processed by XMAS software and an in-house software package for monochromatic microdiffraction analysis. ${ }^{13} \mu \mathrm{XRD}$ data collected in stereographic projection (Figure 3) was integrated along the $2 \theta$ arcs to create 1-D powder diffraction patterns. Peak areas for the 020 reflections for each phase were used for quantitative analysis due to their relatively high intensity/noise ratios (see Supporting information).

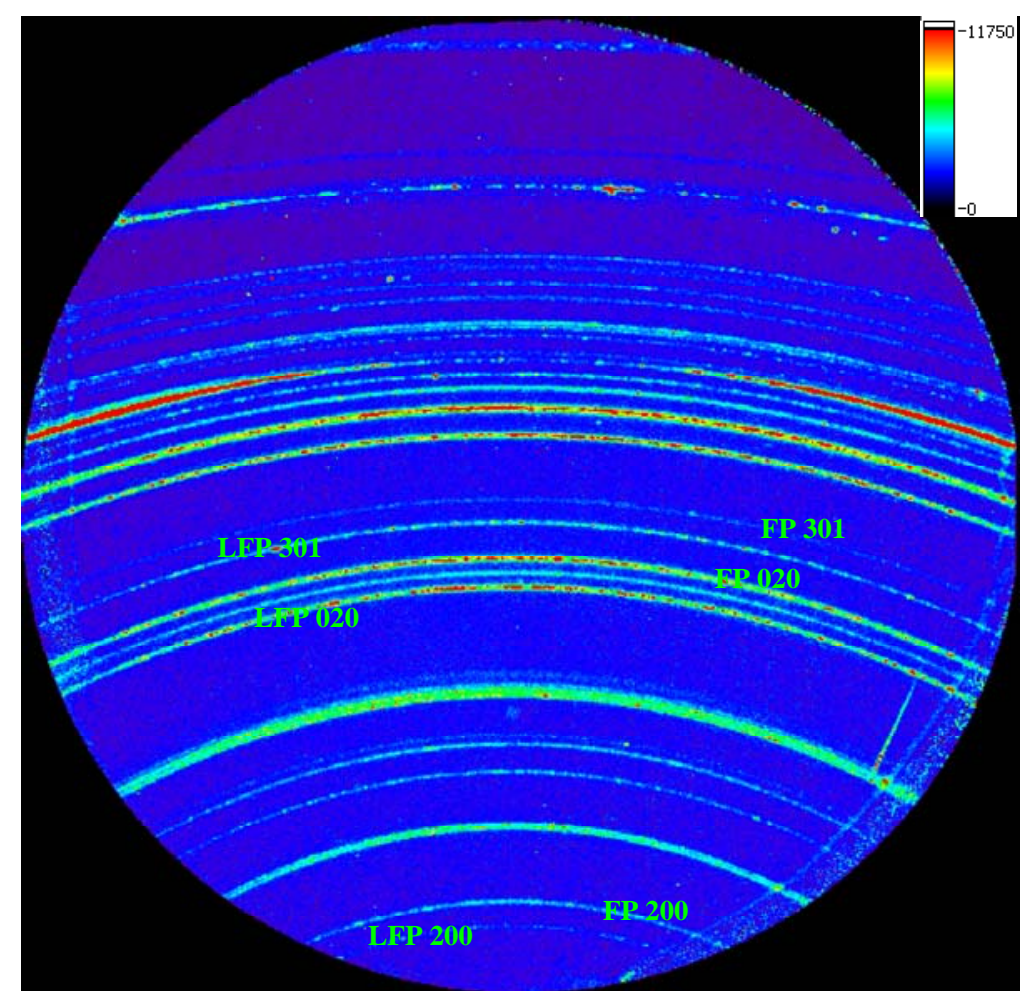

Figure 3. Stereographic XRD patterns of partially charged ( $50 \% \mathrm{SOC}) \mathrm{LiFePO}_{4}$ collected at an energy of $6.02 \mathrm{keV}(\lambda=2.06 \AA)$. Selected peaks for LFP $\left(\mathrm{LiFePO}_{4}\right)$ and FP $\left(\mathrm{FePO}_{4}\right)$ are labeled. The color bar indicates the intensities of the diffraction peaks. Integrated ring intensities correspond to the diffraction peaks in Fig. S1.

SUPPORTING INFORMATION AVAILABLE XRD, Charge-discharge plots, SEM. This material is available free of charge via the Internet at http://pubs.acs.org. 


\section{AUTHOR INFORMATION}

\section{Corresponding Author:}

*To whom correspondence should be addressed. E-mail: tjrichardson@lbl.gov. Tel.: +1-510486-8619. Fax: +1-510-486-8609.

\section{ACKNOWLEDGMENTS}

This work was supported by the Assistant Secretary for Energy Efficiency and Renewable Energy, Office of Vehicle Technologies of the U.S. Department of Energy under Contract No. DE-AC02-05CH11231. The Advanced Light Source is supported by the Director, Office of Science, Office of Basic Energy Sciences, Materials Science Division, of the U.S. Department of Energy under Contract No. DE-AC02-05CH11231 at Lawrence Berkeley National Laboratory. The microdiffraction program at the ALS on beamline 12.3.2 was made possible by NSF Grant No. 0416243. 


\section{References}

1. Armand, M.; Tarascon, J.-M. Building Better Batteries. Nature, 2008, 451, 652-657.

2. Newman, J.; Tiedemann W. Potential and Current Distribution in Electrochemical Cells Interpretation of the Half-Cell Voltage Measurements as a Function of Reference-Electrode Location. J. Electrochem. Soc. 1993, 140, 1961-1968.

3. Verbrugge, M. W. Primary Current Distribution in a Thin-Film Battery. Application to Power-Density Calculations for Lithium Batteries. J. Electrostatics 1995, 34, 61-85.

4. Bakera, D. R.; Verbrugge, M. W. Temperature and Current Distribution in Thin-Film Batteries. J. Electrochem. Soc. 1999, 146, 2413-2424.

5. Dees, D. W.; Battaglia, V. S.; Belanger, A. Electrochemical Modeling of Lithium Polymer Batteries. J. Power Sources 2002, 110, 310-320.

6. Doyle M.; Newman J.; Gozdz, A. S.; Schmutz, C.N.; Tarascon J.-M. Comparison of Modeling Predictions with Experimental Data from Plastic Lithium Ion Cells. J. Electrochem. Soc. 1996, 143, 1890-1903.

7. Reimers, J. N. Predicting Current Flow in Spiral Wound Cell Geometries. J. Power Sources 2006, 158, 663-672. 
8. Kwon, K. H.; Shin, C. B.; Kang, T. H.; Kim, C.-S. A Two-Dimensional Modeling of a Lithium-Polymer Battery. J. Power Sources 2006, 163, 151-157.

9. Kim, U. S.; Shin, C. B.; Kim, C.-S. Effect of Electrode Configuration on the Thermal Behavior of a Lithium-Polymer Battery. J. Power Sources 2008, 180, 909-916.

10. Kim, U. S.; Shin, C. B.; Kim, C.-S. Modeling for the Scale-Up of a Lithium-Ion Polymer Battery. J. Power Sources 2009, 189, 841-846.

11. Díéz-Pérez, I; Güell, A. G.; Sanz, F.; Gorostiza, P. Conductance Maps by Electrochemical Tunneling Spectroscopy To Fingerprint the Electrode Electronic Structure. Anal. Chem. 2006, $78,7325-7329$.

12. Skapin, A. S.; Gaberscek, M.; Dominko, R.; Bele, M.; Drofenik, J.; Jamnik, J. Detection of Highly Conductive Pathways in $\mathrm{LiMn}_{2} \mathrm{O}_{4}$-Carbon Black Composites for Li Ion Batteries by Microcontact Impedance Spectroscopy. Solid State Ionics 2004, 167, 229-235.

13. Kunz, M.; Tamura, N.; Chen, K.; MacDowell, A. A.; Celestre, R. S.; Church, M. M.; Fakra, S.; Domning, E. E.; Glossinger, J. M.; Kirschman, J. L. et al. A Dedicated Superbend X-Ray Microdiffraction Beamline for Materials, Geo-, and Environmental Sciences at the Advanced Light Source. Rev. Sci. Inst. 2009, 80, 035108-1-035108-10. 
14. Goodenough, J. B.; Kim, Y. Challenges for Rechargeable Li Batteries. Chem. Mater. 2010, 22, 587-603.

15. Padhi, A. K.; Nanjundaswamy, K. S.; Goodenough, J. B. Phospho-olivines as PositiveElectrode Materials for Rechargeable Lithium Batteries. J. Electrochem. Soc. 1997, 144, 1188-1194.

16. G. Chen; T. J. Richardson, Continuity and Performance in Composite Electrodes. Journal of Power Sources 2010, 195, 5387-5390.

17. Tamura, N.; MacDowell, A. A.; Spolenak, R.; Valek, B. C.; Bravman, J. C.; Brown, W. L.; Celestre, R. S.; Padmore, H. A.; Batterman, B. W.; Patel, J. R. Scanning X-ray Microdiffraction with Submicron White Beam for Strain/Stress and Orientation Mapping in Thin Films. J. Synchrotron Radiation 2003, 10, 137-143. 